Artigo recebido em:

19.08.2016

Aprovado em:

16.05.2017

Silvia Lisboa

Doutoranda do Programa de Pós-graduação em Comunicação e Informação da UFRGS (Universidade

Federal do Rio Grande do Sul), mestre pelo mesmo Programa e membro

do grupo de pesquisa

Nupejor (Núcleo de Pesquisa em Jornalismo) - UFRGS/CNPq.

E-mail: lisboasilvia@ gmail.com.

\section{Marcia Benetti}

Doutora em Comunicação e Semiótica pela PUC-SP, professora do Programa de Pós-graduação em Comunicação e Informação da UFRGS, pesquisadora do CNPq e líder do grupo de pesquisa Nupejor (Núcleo de Pesquisa em Jornalismo)

- UFRGS/CNPq.

E-mail:marcia.benetti@ gmail.com.

${ }^{1}$ Uma versão preliminar deste texto foi apresentada no XII

Encontro da Associação Brasileira de Pesquisadores em Jornalismo (SBPJor). A versão atual contém revisões importantes.

Estudos em Jornalismo e Mídia Vol. 14 No 1 Janeiro a Junho de 2017 ISSNe 1984-6924

\section{Credibilidade no}

jornalismo: uma nova abordagem $^{1}$

Silvia Lisboa

Marcia Benetti

\section{Resumo}

Este artigo propõe uma abordagem do conceito de credibilidade a partir da articulação do jornalismo com a corrente filosófica da Teoria do Conhecimento e com as teorias discursivas. Credibilidade jornalística é aqui definida como um predicado epistêmico atribuído ao enunciador e a seus relatos. Essa atribuição é feita por alguém, em uma relação intersubjetiva, e amparada em valores éticos e morais. Por só ganhar sentido e relevância através de uma percepção sobre o outro, propomos uma nova abordagem do conceito, através da distinção de duas dimensões: a credibilidade constituída do enunciador e a credibilidade percebida pelo interlocutor. A compreensão de que a credibilidade se desdobra nessas duas dimensões permite qualificar a aplicação do conceito nas pesquisas empíricas.

Palavras-chave: Jornalismo. Credibilidade. Conhecimento.

\begin{abstract}
This article proposes an understanding of the concept of credibility from the fields of journalism, philosophy, specifically the Theory of Knowledge, and the discourse studies. Journalistic credibility is defined here as an epistemic predicate attributed to enunciator and their reports. This assignment is made by someone, in an intersubjective relationship, and supported by ethical and moral values. By only gaining meaning and relevance through a perception about the other, we propose a new approach to the concept, through two-dimensional distinction: the constituted credibility of the enunciator and the perceived credibility by the interlocutor. The understanding that credibility unfolds in these two dimensions allows qualifying the application of the concept in empirical researches.
\end{abstract}

Keywords: Journalism. Credibility. Knowledge. 


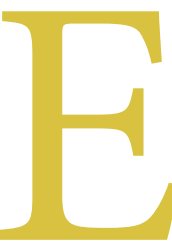

mbora seja um termo frequente na pesquisa em jornalismo, o conceito de credibilidade jornalística tem sido pouco desenvolvido. Afinal, o que significa credibilidade? Qual é a sua definição conceitual? Como os veículos jornalísticos constroem sua credibilidade diante do público? Como o próprio jornalismo, como um campo do conhecimento, adquire ou perde credibilidade? Para enfrentar esse desafio, apresentamos aqui a credibilidade a partir da articulação do jornalismo com a corrente filosófica da Teoria do Conhecimento e com as teorias discursivas.

Em um primeiro momento, buscaremos a conceituação de credibilidade na filosofia para entender como esse predicado epistêmico dos enunciadores e de seus relatos é uma condição vital na obtenção de conhecimento verdadeiro pelo homem. Depois, proporemos uma nova abordagem do conceito, diferenciando suas duas dimensões: a credibilidade constituída e a percebida. Para finalizar, mostraremos como a competência e a integridade de quem fala são indicadores primários de credibilidade.

\section{Credibilidade na filosofia}

De que forma e em que condições o homem obtém conhecimento verdadeiro? Quais atributos tornam uma fonte e seu relato dignos de crédito? Em que situações o julgamento da credibilidade é possível? Esses são alguns dos questionamentos investigados pela filosofia que são úteis para a compreensão do conceito de credibilidade. O interesse dos filósofos da Teoria do Conhecimento se concentra em refletir sobre os aspectos universais envolvidos no processo de conhecimento do homem, sejam os aspectos de natureza individual, sejam os de grandeza coletiva. $\mathrm{O}$ objetivo desses filósofos é mostrar como a percepção do testemunho ${ }^{2}$, como é chamado o relato de terceiros, está baseada em determinados princípios que, não por acaso, permanecem constantes ao longo dos sécu- los - há 2,5 mil anos Aristóteles (1990) já detalhara as evidências capazes de tornar um orador credível ${ }^{3}$.

Se tomarmos o jornalismo como forma e fonte de conhecimento sobre a realidade, podemos pensar o seu funcionamento dentro deste processo universal de busca de conhecimento estudado pela filosofia. O jornalismo seria tributário de um sofisticado sistema de crenças que explica por que atribuímos credibilidade a certos relatos e não a outros. Isto é, o que nos leva a confiar no jornalismo tem a ver não apenas com a sua singularidade como conhecimento, mas com o fato de ele ser um ato comunicativo com a função de informar alguém (LACKEY, 2011). As exigências que fazemos ao jornalismo enquanto fonte de conhecimento e a maneira pela qual julgamos sua credibilidade são, em grande medi$\mathrm{da}$, as exigências e a maneira pela qual atribuímos confiabilidade a qualquer tipo de fonte de informação. Nós temos mecanismos de percepção e de julgamento, desenvolvidos ao longo de anos e que, em condições normais, nos tornam hábeis em perceber inconsistências no discurso alheio, condição absolutamente essencial para a evolução da espécie e para a vida em sociedade.

Em maior ou menor grau, um indivíduo precisa ter confiança na opinião alheia para viver em sociedade. Virtualmente todas as nossas opiniões, com enfoque especial para as opiniões adquiridas através do que os outros nos dizem, são revisadas ao longo do tempo. Por isso, Foley (2004) usa o termo "níveis de confiança", do qual podemos depreender que existem também "níveis de credibilidade", conforme a subordinação do orador a valores que regem sua conduta ética. Ou seja, se não temos absolutamente nenhuma informação, direta ou indireta, que deponha contra quem fala, tendemos a confiar em algum grau no seu relato. Essa confiança é calibrada conforme o seu desempenho em nos dizer "verdades" de um modo plausível.

O homem é um ser social em termos intelectuais. As mais persuasivas e poderosas influências vêm da cultura e
${ }^{2}$ Compartilhamos com Schmitt (2006) a ideia de que o conhecimento que provém dos testemunhos tem um acentuado caráter social. Goldman (1999) criou uma linha de investigação, batizada de Epistemologia Social, para investigar as dimensões sociais que influenciam a formação e a obtenção de conhecimento e crenças verdadeiras.

${ }^{3}$ Segundo Aristóteles (1990), os oradores inspiram confiança com base em três evidências: a prudência (phronesis), a virtude (aretè) e a benevolência (eunoia). 
${ }^{4}$ Isso não significa que não

haja mentiras e boatos circulando socialmente. No entanto, a filosofia compreende que o enunciador que induz a falsas crenças perde sua autoridade discursiva ao longo do tempo, e com isso perde sua importância epistêmica.

${ }^{5}$ Falaremos mais adiante sobre a dimensão da autoridade que integra o conceito de credibilidade.

${ }^{6}$ No original: "Someone who loses her credibility loses the power to induce belief in this way". da tradição, fazendo com que a maioria dos conceitos e suposições que servem de base para nossas crenças não seja autogerada. Grande parte do conhecimento que o homem adquire ao longo da vida não é de primeira mão. Nossa sujeição ao testemunho começa muito precocemente (FRICKER, 2006), muito antes de termos noção do conceito de credibilidade (REID, 2008). A aquisição da linguagem ocorrerá por um processo de confiança das crianças no que é dito por seus pais, professores e cuidadores. Ao longo da vida, outras fontes de conhecimento a memória, o raciocínio, a percepção e a introspecção - se desenvolvem e nos tornam menos dependentes do relato dos outros. Ainda assim, o testemunho pode continuar sendo a principal fonte de crenças verdadeiras. Muito do que sabemos sobre o mundo e sobre nós mesmos nos chega por meio de relatos de familiares, amigos, professores - e do jornalismo.

A percepção sobre a credibilidade do orador é uma questão essencial na vida em sociedade. Apesar de não haver uma definição exata na filosofia, a credibilidade no campo é entendida como um predicado epistêmico dos enunciadores e seus relatos (LISBOA, 2012). O conceito está fundamentalmente associado ao de confiança, e seu significado mais usual é o de confiabilidade. A credibilidade seria uma característica do que é confiável, e a confiança pode ser compreendida como um comportamento, uma expectativa em relação à atitude de alguém ou ao desempenho de algo (LUHMANN, 1996; GIDDENS, 1991). Confiar em alguém pressupõe uma avaliação da credibilidade (ou confiabilidade) desse alguém. A credibilidade, portanto, seria um elemento essencial da confiança, sendo resultado de uma percepção da qualidade do testemunho, realizada pelo interlocutor a partir de certos indicadores e situações (LISBOA, 2012). Uma avaliação positiva da credibilidade do enunciador é capaz de gerar confiança - e por essa razão, em muitos momentos, as noções acabam sendo usadas como sinônimos.

A confiança e a atribuição de cre- dibilidade pressupõem a existência de regras segundo as quais a verdade seria obrigatória $^{4}$ - não pelo sentido metafísico, mas por sua utilidade social para os indivíduos envolvidos no ato de comunicação. É porque perseguimos a verdade que tiramos dúvidas específicas com fontes de informação com autoridade no assunto $^{5}$ e não com qualquer um (GOLDMAN, 1999).

Baseando-se na premissa aristotélica de que todo homem deseja conhecer, Goldman (1999) considera a busca da verdade, ou de uma aproximação da verdade, uma das questões mais pervasivas da vida do homem. Reid (2008) foi o primeiro a formular dois princípios da veracidade do testemunho até hoje citados em estudos da área: 1) temos propensão a dizer a verdade; 2) temos disposição a confiar no que os outros nos dizem. Para Reid, a verdade é um impulso natural da mente humana. Já mentir seria uma violência contra a natureza do homem, e nem o pior dos indivíduos a praticaria senão movido por uma tentação. "Alguém que perde credibilidade perde seu poder de induzir a crença no seu relato" (WEINER, 2009, p. 22, tradução nossa $\left.{ }^{6}\right)$. A credibilidade serviria como uma espécie de fiança para justificar uma crença, que pode ser perdida se ela se provar falsa.

Esse aspecto revela o caráter do conceito de credibilidade. A credibilidade é um predicado que está amparado em valores éticos e morais. Isso porque a avaliação sobre a fonte de informação dirá se ela é um bom ou um mau informante de acordo com o que se esperava dela e de acordo com o contexto da comunicação, que tornou possível essa percepção. O próprio fato de o conhecimento ser um bem socialmente compartilhado concede à noção uma dimensão ética, porque envolve a relação entre indivíduos que compartilham interesses e objetivos (FRICKER, 2011) e torna os testemunhos uma prática governada por normas. Tanto o orador quanto o interlocutor obedecem a normas que têm um caráter eminentemente operacional. Podemos usar o exemplo de Millar (2010) 
sobre o jogo de futebol para mostrar como a existência de regras forma o quadro de referência dentro do qual um discurso tem lugar. Uma partida de futebol tem dois tempos de 45 minutos, 11 jogadores de cada lado e uma série de regras que indicam que falta na área é pênalti e dois cartões amarelos significam expulsão. Ao entrar em campo, os jogadores - supostamente - sabem como agir para ganhar a partida e não cometem faltas gratuitas que possam colocar o time a perigo. Eles têm um contrato virtual sobre o que fazer ou não fazer em campo, e existe um limite de anarquia que o futebol suporta até que deixe de ser considerado futebol. No jornalismo não é diferente: as regras de seu funcionamento exigem determinadas práticas e acionam determinados valores, sem os quais ele deixará de ser jornalismo.

\section{Credibilidade constituída e credibilidade percebida}

A acurácia de um discurso está sob domínio do enunciador, que precisa deixar claras as suas intenções e dar garantias da veracidade do que está sendo dito. A forma do discurso e a exposição das intenções terão um impacto preponderante na percepção da credibilidade pelo interlocutor. Segundo Serra, a relação entre a credibilidade do orador e a credibilidade de seu discurso é dialética:

[...] é, por um lado, uma relação em que as qualidades de cada um dos elementos vão se repercutindo no outro - o orador vai se tornando credível à medida que o seu discurso se torna credível, e reciprocamente - e é, por outro lado, uma relação dinâmica, que progride, pelo menos idealmente, do menos para o mais. Mas, para que esta relação dialética se torne efetiva, exige-se que o orador e o discurso sejam capazes de instaurar, com o auditório e o seu "discurso" interior e silencioso - as suas crenças, os seus valores -, um certo tipo de relação (SERRA, 2006a, p. 2-3).
A abordagem de Serra reforça a importância de não se incorrer no equívoco comum de pensar que a credibilidade pode ser somente uma qualidade auto-atribuída por quem fala. Para que a credibilidade seja atribuída como um predicado, é preciso haver uma correspondência entre a construção da credibilidade pelo enunciador e a percepção desse predicado por parte do interlocutor, isto é, uma relação entre o que chamamos aqui de a credibilidade constituída do orador e a credibilidade percebida pelo interlocutor ${ }^{7}$ (LISBOA, 2012). Trata-se de uma distinção da ordem da percepção, baseada na condição de conhecimento de Kant (1970).

Kant estabelece uma diferenciação entre a "coisa em si" (númeno) e a "coisa para nós" (fenômeno), mostrando que os objetos existem independentemente da nossa percepção, mas é somente através dela que podemos conhecê-los. Logo, a credibilidade, enquanto atributo de qualidade do enunciador ou de seu discurso, seria dependente da perspectiva de um outro sujeito. A credibilidade constituída de um orador precisa preexistir $^{8}$ à percepção do interlocutor, mas só ganha sentido dentro de uma relação intersubjetiva. Aqui temos uma relação complexa e dinâmica. Não estamos dizendo que a credibilidade constituída exista desde sempre como uma essência. Essa dimensão da credibilidade, que é anterior à credibilidade efetivamente percebida pelo interlocutor, está ancorada em valores, princípios e práticas que foram se constituindo historicamente como importantes para que a confiança se estabeleça. Esses valores, que também não são imutáveis, indicam grande parte das expectativas que a audiência terá sobre o jornalismo e, claro, indicam o que o enunciador deve fazer para parecer confiável. Os atributos que sustentam a credibilidade precisam ser de alguma forma incorporados ao sujeito que enuncia para serem percebidos pelo sujeito que interpreta. E, ainda que o interlocutor nada saiba especificamente sobre o orador, há elementos que indicam o que se pode esperar dele: "De fato, mesmo que
${ }^{7}$ Agradecemos aqui ao filósofo Eros Moreira de Carvalho por nos ajudar a perceber essa distinção conceitual.

${ }^{8}$ Esses atributos preexistentes caracterizam o que Haddad (2013) chama de ethos prévio. O ethos prévio do jornalismo implica uma presunção de credibilidade (BURGE, 1993). 
${ }^{9}$ Há pequenas divergências nos textos consultados sobre a relação dos atributos que tornam uma fonte confiável. Em um trabalho de 1994, Fricker (apud MILLAR, 2011) afirma que sinceridade e competência são atributos do caráter da fonte. Posteriormente, ela separa do caráter da fonte o componente da competência, talvez por considerar este último um aspecto de ordem técnica. Essa sistematização parece mais clara, de modo que a adotamos neste trabalho. o coenunciador não saiba nada previamente sobre o caráter do enunciador, o simples fato de que um texto pertence a um gênero de discurso ou a um certo posicionamento ideológico induz expectativas em matéria de ethos" (MAINGUENEAU, 2013, p. 71).

$\mathrm{O}$ ethos se constitui a partir de um conjunto de atributos ou valores. No caso do jornalismo, isso significa que a credibilidade será acionada como uma expectativa sempre que um texto for percebido, pelo interlocutor, como um texto jornalístico. É importante ponderar ainda que o sujeito está sempre socialmente situado, e estes lugares - de fala ou de interpretação - também definem a qualidade de sua enunciação ou de sua percepção.

O enunciador não é um ponto de origem estável que se "expressaria" dessa ou daquela maneira, mas é levado em conta em um quadro profundamente interativo, em uma instituição discursiva inscrita em uma certa configuração cultural e que implica papéis, lugares e momentos de enunciação legítimos, um suporte material e um modo de circulação para o enunciado (MAINGUENEAU, 2013, p. 75).

No âmbito do conhecimento e do discurso, a credibilidade constituída ganha relevância através da percepção de alguém, por meio da credibilidade percebida. Isso significa que um sujeito pode se construir discursivamente como um enunciador credível, baseado em atributos valorizados como competência, honestidade, coerência. Mas a audiência precisa reconhecê-la como tal para que o conceito ganhe valor. A credibilidade percebida pelo leitor sofre influência direta da credibilidade constituída, mas não necessariamente estará fundada em todos os mesmos valores e princípios. Esta é a contribuição conceitual que pretendemos trazer com este artigo. É importante compreender que, ao pesquisar credibilidade, precisamos distinguir estes dois horizontes de pro- blemas: o que diz respeito a uma noção mais ampla, inclusive histórica e ética, sobre o que sustenta a confiança em uma fonte de conhecimento (no nosso caso, o jornalismo), e o que diz respeito à credibilidade efetiva, mensurável, percebida pelos demais sujeitos (no nosso caso, a audiência). Embora essas dimensões credibilidade constituída e percebida sejam complementares, elas são distintas e podem exigir procedimentos metodológicos também distintos para serem pesquisadas.

\section{Competência e integridade: princípios da credibilidade}

A credibilidade constituída está amparada em noções socialmente compartilhadas sobre o que significa ser "um bom informante", ou seja, noções de caráter moral. Esses aspectos, já identificados por Aristóteles, permanecem praticamente os mesmos até hoje. São eles: a) a competência, também chamada de autoridade, que se refere ao conhecimento técnico e verdadeiro sobre o assunto abordado, e b) a integridade da fonte, que envolve tópicos relativos ao seu caráter, como a disposição em compartilhar informações, o compromisso com a verdade, a sinceridade em expor motivações e interesses e, sobretudo, a reputação. Esses aspectos estão presentes tanto nos trabalhos filosóficos de Aristóteles (1990), Coady (2000), Audi (2003, 2006), Goldman (2002), Lackey (2006) e Fricker $(2011)^{9}$, como em pesquisas de comunicação de Hovland e Weiss (1951, 1959) e Fogg et al (2001a, 2002a).

Aspectos como competência e integridade podem ser decompostos em indicadores que tornam possível avaliar o nível de credibilidade de uma fonte e seu discurso. Pode-se exigir que um bom informante não tenha interesses persuasivos ou escusos, seja objetivo, coerente e responsável. Nesse caso, seu discurso também deve carregar esses índices, que irão permitir o julgamento da credibilidade percebida pelo interlocutor. As propriedades discursivas sinalizam para o leitor a presença de ambos os aspectos: 
competência e integridade. Aristóteles (1990) e Moran (2006) acreditam que um discurso diz não apenas do assunto em questão, mas da pessoa que o profere. As escolhas feitas em um discurso servem como prova das intenções do que foi dito, podem revelar aspectos não falados pela fonte que ajudarão o interlocutor a formar impressões sobre ela e sobre seu relato. A competência é tão relevante na atribuição da credibilidade, que muitos autores a consideram como uma condição.

A integridade e a autoridade de quem fala se tornam, assim, indicadores primários da credibilidade. Se entendermos que a reputação integra os dois aspectos, já que é resultado da percepção que a audiência tem do enunciador - a partir de informações sobre seu discurso e sobre seu comportamento ao longo do tempo -, podemos incluir a reputação como um dos atributos primários da credibilidade constituída. Primário, neste caso, refere-se a primeiro, elementar. Esse é um dos motivos pelos quais os conceitos de reputação e autoridade têm sido, em alguns estudos empíricos, usados como sinônimos de credibilidade ${ }^{10}$. Não se pode confundi-los, mas é correto afirmar que, quando se olha para um, vêse o outro (FOGG, et. al., 2001b).

Um exemplo trazido por Fogg (et. al., 2001b) sobre como um site jornalístico se torna credível ilustra como as dimensões de competência e integridade se desdobram na prática. A maior parte dos indicadores que servem como um guia para aferição da credibilidade de um site são tentativas de demonstrar ao leitor como ele pode atestar o quanto aquela fonte tem competência e qual seu grau de honestidade e isenção. São eles:

1) facilitar a verificação, pelo leitor, da veracidade das informações apresentadas, linkando textos de referências e fontes reconhecidas; 2) deixar claro que existe uma organização real por trás do site, com a lista dos membros e seus endereços físicos com fotos; 3) expor e valorizar a competência das pes- soas que produzem o conteúdo; 4) demonstrar, através de textos e imagens, que você é confiável ou que os serviços que você ou sua empresa prestam são confiáveis; 5) colocar, de forma visível e acessível, o telefone e endereço fixo da empresa para que o leitor possa entrar em contato; 6) investir no design do site; 7) torná-lo útil e relevante; 8) atualizá-lo com frequência e deixar essa informação visível; 9) evitar colocar anúncios, mas, se isso for necessário, diferenciar o conteúdo pago do editorial; 10) evitar erros de qualquer tipo, por menores que eles sejam (FOGG, 2002, tradução nossa ${ }^{11}$ ).

A autoridade (CHARAUDEAU, 2010) é um dispositivo integrante do contrato de comunicação, que se sustenta na crença de que o jornalismo é uma prática especializada a narrar a realidade. Ou seja, o jornalismo constitui-se como uma fonte credível dando provas de que está comprometido com a verdade dos fatos, de que é íntegro nas suas razões e conduta. As dimensões autoridade e integridade, portanto, se entrelaçam e sustentam a confiança de que o jornalismo é um sistema perito ${ }^{12}$. Conforme Miguel (1999, p. 199, grifo do autor):

O leitor/ouvinte/ espectador, no papel de consumidor de notícias, mantém em relação ao jornalismo uma atitude de confiança, similar à dos outros sistemas peritos, que pode ser dividida em três momentos: 1) confiança quanto à veracidade das informações relatadas; 2 ) confiança quanto à justeza na seleção e hierarquização dos elementos importantes ao relato; 3 ) confiança quanto à justeza na seleção e hierarquização das notícias diante do estoque de 'fatos' disponíveis.

É importante destacar que a avaliação da credibilidade do enunciador não é apenas individual. É também coletiva e condicionada por fatores culturais, so-
${ }^{10} A$ confusão conceitual tem uma origem histórica. Antes das pesquisas do grupo de Yale, a credibilidade era tratada apenas como "prestígio" (EARLE e CVETKOVICH, 1995).

${ }^{11}$ O guideline da credibilidade, elaborado pelo grupo de Stanford, pode ser encontrado no site http://credibility. stanford.edu/guidelines/ index.html. "1) Make it easy to verify the accuracy of the information on your site. 2) Show that there's a real organization behind your site. 3) Highlight the expertise in your organization and in the content and services you provide.4) Show that honest and trustworthy people stand behind your site. 5) Make it easy to contact you. 6) Design your site so it looks professional (or is appropriate for your purpose). 7) Make your site easy to use - and useful. 8) Update your site's content often (at least show it's been reviewed recently). 9) Use restraint with any promotional content (e.g., ads, offers). 10) Avoid errors of all types, no matter how small they seem."

${ }^{12}$ Miguel (1999) apropria-se do conceito de expert systems (sistemas especialistas ou sistemas peritos) de Giddens (1991). 
${ }^{13}$ Pesquisas norte-americanas datadas dos anos 1990 revelaram que entrevistas pessoais para selecionar candidatos eram más ferramentas de avaliação porque os avaliadores se prendiam a aspectos da aparência, maneirismos e outras informações superficiais que, apesar de irrelevantes, se tornavam salientes e acabavam pesando mais do que deveriam. A escolha baseada em desempenho escolar e outros dados objetivos e técnicos demonstrou ser mais eficaz na seleção do melhor profissional, mas era constantemente relegada. Foley (2004) cita as descobertas expostas por Robyn Dawes no livro House of cards (New York: The Free Press, 1994).

${ }^{14}$ Sobre a verdade como correspondência, sugerimos Abbagnano (2007), Chaui (2001), Goldman (1999) e Kirkham (2003). ciais e econômicos. Apesar do enfoque racional dado à avaliação da credibilidade do testemunho, o julgamento da credibilidade de um relato escrito ou falado também ocorre em níveis não racionais ou não totalmente cobertos pela razão (FOLEY, 2004). Aspectos aparentes, como o modo de vestir do jornalista, a exposição de sua orientação sexual ou a diagramação de um jornal ou revista também podem afetar a aferição do nível de credibilidade ${ }^{13}$. São frequentemente usados em situações de comunicação, apesar de não serem indicadores confiáveis na atribuição de credibilidade de pessoas e discursos no sentido de sua veracidade. A pobreza, por exemplo, pode ser um indicador negativo de credibilidade, assim como a riqueza pode ser um indicador positivo - ou o contrário, dependendo do interlocutor. O mesmo pode ocorrer com a etnia ou o status social. Quando apenas esses fatores são considerados, ocorre o que Fricker (2011) chama de injustiça epistêmica. A credibilidade, então, como constata Marsh (2011), é um tipo de poder social.

Esses fatores estão intimamente associados a ideologias e condições sócio -históricas que determinam as estruturas de poder vigentes. No caso do jornalismo, temos um conhecimento estruturado sobre determinados valores, e esta estruturação é amplamente difundida na sociedade. Frequentemente os próprios jornalistas constroem "representações de suas ações e de suas palavras, às quais atribuem valores" (CHARAUDEAU, 2010, p. 73). Ainda que nem sempre essas representações correspondam à prática, a associação entre elas e "o bom jornalismo" é reiterada em diversos lugares: em editoriais publicados pelos veículos, em livros escritos e conferências proferidas por jornalistas, em documentários sobre reportagens importantes, em filmes e novelas, em manuais de redação, em pesquisas acadêmicas. Todo leitor tem, no horizonte, um leque de expectativas em relação ao jornalismo, e essas expectativas foram paulatinamente sendo consolidadas por todos esses discursos, além da própria experiência da leitu- ra. Um tema importante referente a essas expectativas é a função social do jornalismo. "Para que serve o jornalismo?", perguntam Kovach e Rosenstiel (2001, p. 16), respondendo em seguida que sua principal finalidade "é fornecer aos cidadãos a informação de que precisam para serem livres e se autogovernarem". Para Reginato (2016), que estudou o discurso de veículos, leitores e jornalistas sobre o tema, o jornalismo tem 12 finalidades:

Na minha perspectiva, o jornalismo deve servir para: a) informar de modo qualificado; b) investigar; c) verificar a veracidade das informações; d) interpretar e analisar a realidade; e) fazer a mediação entre os fatos e o leitor; $\mathrm{f}$ ) selecionar o que é relevante; $g$ ) registrar a história e construir memória; h) ajudar a entender o mundo contemporâneo; i) integrar e mobilizar as pessoas; $\mathrm{j}$ ) defender o cidadão; $\mathrm{k}$ ) fiscalizar o poder e fortalecer a democracia; l) esclarecer o cidadão e apresentar a pluralidade da sociedade. (REGINATO, 2016, p. 233).

O que ocorre, na aferição da credibilidade, é a relação entre o que o leitor efetivamente percebe e aquilo que sabia de antemão sobre o que deveria ser o jornalismo e que, portanto, dele esperava. A credibilidade, então, aumenta ou diminui segundo essas relações, pois depende da expectativa formada pelos sujeitos.

Dois princípios deontológicos estão na base da credibilidade constituída do jornalismo: a verdade, associada à integridade, e o interesse público, associado à competência. A busca de uma verdade como correspondência ou conformidade ao real ${ }^{14}$ sobre fatos que sejam relevantes a uma comunidade, e não apenas a um grupo, é norteadora do ethos jornalístico. Como dizem Kovach e Rosenstiel (2001, p. 36), "a primeira obrigação do jornalismo é para com a verdade". Franciscato (2005, p. 166, grifo nosso) também coloca a verdade como correspondência no centro da definição do jornalismo: "[a atividade jornalística 
adota] como pressuposto a existência de uma ideia de verdade do real que pode ser apreendida nos seus aspectos principais por meio de técnicas jornalísticas e transformada em relato noticioso". O jornalismo opera "com base em um sentido de fidelidade entre o relato jornalístico e as ocorrências cotidianas" (FRANCISCATO, 2005, p. 167). É interessante também considerar a definição de Goldman (1999) da verdade como um conceito pós-semântico: é apenas depois de uma proposição ou de qualquer outra coisa que carregue um sentido de verdade que a questão sobre a verdade pode ser levantada. Em se tratando de jornalismo, esse questionamento exigirá voltar aos fatos e aos testemunhos.

O interesse público é um princípio que se refere ao campo da competência ou autoridade do jornalismo. Não há uma definição consensual do que seja exatamente interesse público, que de modo geral costuma ser tomado como o que diz respeito à maioria ou à esfera pública. Como diz Cornu (1994, p. 403), “a informação jornalística concerne a uma verdade que interessa à sociedade civil e não à esfera privada”. Sartor (2016) afirma que o conceito de interesse público se concretiza, para os jornalistas, a partir das noções de relevância pública ${ }^{15}$, esclarecimento, vigilância, espaço comum e preferência de consumo. O jornalismo é ativo no processo de atribuição de um caráter público a temas e acontecimentos (SARTOR, 2016) e por isso exerce grande poder. No que diz respeito à credibilidade, o jornalismo será avaliado a partir da capacidade de selecionar o que é publicamente relevante, de articular temas importantes ao debate sobre cidadania e de investigar a retidão de outros atores sociais.

A busca pela verdade e o compromisso com o interesse público constituem a base da credibilidade constituída do jornalismo, assim como norteiam o primeiro movimento de leitura da credibilidade percebida pelo leitor ou interlocutor. Outros valores - alguns polêmicos - podem ser agregados ao ethos jornalístico, como independência, imparcia- lidade, objetividade, precisão, equilíbrio e coerência. Sendo a credibilidade o principal capital do campo jornalístico (BERGER, 1996), aquilo que lhe confere maior ou menor valor, o certo é que a confiança depositada pelos leitores nos jornalistas e veículos depende da consonância entre o dever-ser do jornalismo e aquilo que percebem que é efetivamente praticado.

\section{Considerações finais}

O objetivo deste artigo foi conceituar credibilidade jornalística a partir da contribuição da filosofia e das teorias do discurso. Nesse percurso, pensamos a crença no jornalismo como tributária de um processo universal de busca por conhecimento verdadeiro sobre o qual a Teoria do Conhecimento se debruça. Ao inseri-lo nessa perspectiva filosófica e também discursiva, conseguimos ver como o jornalismo se constrói como um mediador crível da realidade amparando-se em aspectos como competência e integridade, indicados já por Aristóteles como essenciais. Esses aspectos, socialmente partilhados e consolidados ao longo do tempo, contribuem para sustentar a compreensão da audiência sobre o dever-ser do jornalismo.

É esse jogo dialético que torna necessária a distinção que aqui propusemos entre duas dimensões do conceito de credibilidade: a de credibilidade constituída do jornalismo e a da credibilidade percebida pela audiência. A credibilidade constituída diz respeito ao perfil do enunciador (jornalista, veículo jornalístico ou o próprio jornalismo) e do quanto ele se aproxima das dimensões ideais e socialmente reconhecidas sobre o que torna um enunciador digno de confiança. Há também questões de natureza subjetiva que são de difícil mensuração, mas que não podem ser desprezadas porque impactam na percepção do que é um orador credível. Já a credibilidade percebida é resultado da avaliação que o leitor faz do jornalismo a partir de indicadores presentes na credibilidade constituída.

Ninguém nega a importância da
${ }^{15} \mathrm{Nem}$ sempre o que é indicado como se tivesse interesse público diz respeito ao interesse da maioria: "[...] a noção de interesse público comporta uma dimensão normativa, referente a valores, princípios e interpretações desenvolvidas em nível teórico-prescritivo, $e$ outra dimensão empírica, relacionada ao modo pelo qual o interesse público é socialmente construído. Nesse caso, também a dimensão normativa condiciona apenas parcialmente a dimensão empírica, e pode acontecer ainda de se atribuir uma qualidade de interesse público a temas, questões, acontecimentos decisões e ações que correspondem a interesses privados ou de grupos sociais específicos, os quais, por meio de estratégias discursivas (ou de outra natureza), conseguem conferir um estatuto de universalidade às suas próprias pretensões e vontades" (SARTOR, 2016, p. 119, grifo do autor). 
${ }^{16} \mathrm{~A}$ investigação sobre este prisma foi realizada na dissertação "Jornalismo e a credibilidade percebida pelo leitor: independência, imparcialidade, honestidade, objetividade e coerência", defendida em 2012. credibilidade nos estudos do campo e a centralidade do conceito particularmente neste momento de crise, em que se repensam questões centrais como a identidade, a legitimidade e os valores do jornalismo. A credibilidade é ainda hoje muito citada nos estudos, porém pouco investigada. Nosso objetivo foi analisar a natureza do conceito e suas dimensões, de modo que futuros estudos possam investigar outros aspectos associados a ela, como as bases da credibilidade constituída, da percebida ${ }^{16}$ e a relação entre ambas em diferentes situações e contextos; os fatores culturais e históricos que impactam na crença; as percepções de credibilidade entre diferentes públicos quanto ao dever-ser do jornalismo; o impacto dos novos suportes sobre a percepção de credibilidade, entre outros.

Como desenvolvemos em outro trabalho (LISBOA, BENETTI, 2015), o jornalismo se torna um tipo de conhecimento por meio de um processo de justificação, o que significa dizer que o jornalismo é uma crença verdadeira justificada: os pilares da verdade e da justificação (provas e evidências de veracidade) sustentam a crença dos sujeitos na validade de seu discurso. É desta forma que a credibilidade se constrói como um predicado epistêmico, que está amparado em valores éticos e condicionado por fatores históricos, culturais e sociais.

\section{Referências}

ABBAGNANO, Nicola. Dicionário de filosofia. São Paulo: Martins Fontes, 2007.

ARISTÓTELES. Retórica. Madri: Centro de Estudios Constitucionales, 1990.

AUDI, Robert. Epistemology: a contemporary introduction to theory of knowledge. Londres: Routledge, 2003.

AUDI, Robert. Testimony, credulity and veracity. In: LACKEY, Jennifer; SOSA, Ernest (org.). Epistemology of testimony. Nova York: Oxford, 2006.

BERGER, Christa. Em torno do discurso jornalístico. In: NETO, Antonio Fausto; PINTO, Milton José (org.). O indivíduo e as mídias. Rio de Janeiro: Diadorim, 1996.

BURGE, Tyler. Content Preservation. Philosophical Review, vol. 102, n. 4, 1993.

CHARAUDEAU, Patrick. Discurso das mídias. São Paulo: Contexto, 2010.

CHAUI, Marilena. Convite à filosofia. São Paulo: Ática, 2001.

COADY, Cecil Anthony John. Testimony: a philosophical study. Oxford: Oxford University Press, 2000.

CORNU, Daniel. Jornalismo e verdade: para uma ética da informação. Lisboa: Instituto Piaget, 1994.

DAWES, Robyn. House of cards. Nova York: The Free Press, 1994.

EARLE, Timothy; CVETKOVICH, George. Social Trust: toward a cosmopolitan society. Westport (EUA): Praeger Publishers, 1995. 
FOGG, B. J. et al. Web credibility research: a method for online experiments and some early study results. Proceedings of ACM CHI, vol. 2. Nova York: ACM Press, 2001a. Disponível em: < http://captology.stanford.edu/>. Acesso em: 15 fev. 2011.

FOGG, B. J. et al. What makes a web site credible? A report on a large quantitative study. Proceedings of ACM CHI. 2001b. Disponível em: < http://captology.stanford. edu/>. Acesso em: 10 jul. 2010.

FOGG, B. J. et al. Stanford-Makovsky Web Credibility Study 2002: investigating what makes a web site credible today. 2002. Disponível em: http://captology.stanford.edu. Acesso em: 10 jul. 2010.

FOLEY, Richard. Intellectual trust in oneself and others. Cambridge: Cambridge University Press, 2004.

FRANCISCATO, Carlos Eduardo. A fabricação do presente: como o jornalismo reformulou a experiência do tempo nas sociedades ocidentais. São Cristóvão: Editora UFS, 2005.

FRICKER, Miranda. Rational authority and social power: towards a truly Social Epistemology. In: GOLDMAN, Alvin; WHITCOMB, Dennis (org.). Social Epistemology. Nova York: Oxford University Press, 2011.

FRICKER, Elizabeth. Testimony and epistemic autonomy. In: LACKEY, Jennifer; SOSA, Ernest (org.). Epistemology of testimony. Nova York: Oxford, 2006.

GIDDENS, Anthony. As consequências da modernidade. São Paulo: Editora da Unesp, 1991.

GOLDMAN, Alvin. Knowledge in a social world. Oxford: Oxford University Press, 1999.

GOLDMAN, Alvin. Pathways to knowledge. Oxford: Oxford University Press, 2002.

GRAHAM, Peter. Testimonial entitlement and the function of comprehension. In: HADDOCK, Adrian; MILLAR, Alan; PRITCHARD, Duncan (org.). Social Epistemology. Nova York: Oxford University Press, 2010.

HADDAD, Galit. Ethos prévio e ethos discursivo: o exemplo de Romain Rolland. In: AMOSSY, Ruth (org.). Imagens de si no discurso: a construção do ethos. 2.ed. São Paulo: Contexto, 2013.

HOVLAND, Carl et al. Communication and persuasion: physicological studies of opinion change. New Haven: Yale University Press, 1959.

HOVLAND, Carl; WEISS, Walter. The influence of source credibility on communication effectiveness. Public Opinion Quarterly, vol. 15, 1951. Disponível em: $<\mathrm{http}: / /$ www.radford.edu/ jaspelme/443/spring-2007/Articles/Hovland_n_Weiss_1951_ sleeper-effect.pdf. Acesso em: 2 de abr. 2016.

KANT, Emmanuel. Crítica da razão pura. Rio de Janeiro: Edições de Ouro, 1970. 
KIRKHAM, Richard L. Teorias da verdade. São Leopoldo: Editora Unisinos, 2003.

KOVACH, Bill; ROSENSTIEL, Tom. Os elementos do jornalismo: o que os profissionais devem saber e o público deve exigir. Porto: Editora Porto, 2001.

LACKEY, Jennifer. Testimonial knowledge. In: BERNECKER, Sven; PRITCHARD, Duncan (org.). The Routledge Companion to Epistemology. Londres/ NovaYork: Routledge, 2011.

LACKEY, Jennifer. It takes two to tango: beyond reductionism and non-reductionism in the epistemology of testimony. In: LACKEY, Jennifer; SOSA, Ernest (org.). Epistemology of testimony. Nova York: Oxford, 2006.

LISBOA, Sílvia Saraiva de Macedo. Jornalismo e a credibilidade percebida pelo leitor: independência, imparcialidade, objetividade, honestidade e coerência. Dissertação (Mestrado em Comunicação e Informação). Porto Alegre: UFRGS, 2012.

LISBOA, Silvia; BENETTI, Marcia. O jornalismo como crença verdadeira justificada. Brazilian Journalism Research. V. 2, N. 2. Brasília: SBPJor, 2015.

LUHMANN, Niklas. Confianza. México: Anthropos, 1996.

MAINGUENEAU, Dominique. Ethos, cenografia, incorporação. In: AMOSSY, Ruth (org.). Imagens de si no discurso: a construção do ethos. 2.ed. São Paulo: Contexto, 2013.

MARSH, Gerald. Trust, testimony and prejudice in the credibility economy. Hypatia, Volume 26, n. 2, 2011.

MIGUEL, Luís Felipe. O jornalismo como sistema perito. Tempo Social. Revista de Sociologia da USP. V. 11, n. 1. São Paulo: USP, 1999.

MILLAR, Alan. Knowing from being told. In: HADDOCK, Adrian; MILLAR, Alan; PRITCHARD, Duncan (org.). Social Epistemology. Nova York: Oxford University Press, 2010.

MORAN, Richard. Getting told and being believed. In: LACKEY, Jennifer; SOSA, Ernest (org.). Epistemology of testimony. Nova York: Oxford, 2006.

REGINATO, Gisele Dotto. As finalidades do jornalismo: o que dizem veículos, jornalistas e leitores. Tese (Doutorado em Comunicação e Informação). Porto Alegre: UFRGS, 2016.

REID, Thomas. Essays on the intellectual powers of man. 2008. Disponível em: $<$ http://www.earlymoderntexts.com>. Acesso em: 29 jun. 2016.

SARTOR, Basilio Alberto. A noção de interesse público no jornalismo. Tese (Doutorado em Comunicação e Informação). Porto Alegre: UFRGS, 2016.

SCHMITT, Frederick. Transindividual reasons. In: LACKEY, Jennifer; SOSA, Ernest (org.). Epistemology of testimony. Nova York: Oxford, 2006.

SERRA, Paulo. A credibilidade da informação na web. Biblioteca On-line de Ciên- 
cias da Comunicação. 2006a. Disponível em: <http://www.bocc.ubi.pt/pag/serra -paulo-credibilidade-web.pdf>. Acesso em: 12 ago. 2010.

SPERBER, Dan. An evolutionary perspective on testimony and argumentation. Philosophical Topics, n. 29, 2001.

WEINER, Matthew. The Assurance View of Testimony. 2009. Disponível em:

http://mattweiner.net/papers/weiner_assurance_view.pdf. Acesso em: 15 jun. 2016. 